\title{
WEIGHTED MIXED NORM INEQUALITIES IN MARTINGALE SPACES
}

\author{
Wei Chen AND PEIDE LiU
}

Abstract. For the maximal geometric mean operator $G$ in martingale spaces, we characterize the weight paries $(u, v)$ for which $G$ is bounded from martingale space $L^{p}(v d \mu)$ to $w L^{q}(u d \mu)$ or $L^{q}(u d \mu), 1 \leqslant p \leqslant q<\infty$.

Mathematics subject classification (2010): Primary 60G46; Secondary 60G42.

Keywords and phrases: Martingale, maximal geometric mean operator, weighted inequality, weight.

\section{REFERENCES}

[1] B. Muckenhoupt, Weighted norm inequalities for the Hardy maximal function, Trans. Amer. Math. Soc., 165 (1972), 207-226.

[2] C. Sbordone And I. Wik, Maximal functions and related weight classes, Publ. Mat., 38 (1994), $127-155$.

[3] S. V. Hruscev, A description of weights satisfying the $A_{\infty}$ condition of Muckenhoupt, Proc. Amer. Math. Soc., 90 (1984), 253-257.

[4] X. L. SHI, Two inequalities related to geomrtric mean operators, J. Zhejiang Teacher's College, 1 (1980), 21-25.

[5] X. Q. YIN AND B. MUCKENHOUPT, Weighted inequalities for the maximal geometricmean operator, Proc. Amer. Math. Soc., 124 (1996), 75-81.

[6] W. Hu, X. L. SHI AND Q. Y. SUn, $A_{\infty}$ condition characterized by maximal geometric mean operator, Lecture Notes in Math., vol. 1494, Springer-Verlag, New York, 1991, pp. 68-72.

[7] D. CruZ-Uribe And C. J. Neugebauer, The structure of the reverse Hölder classes, Trans. Amer. Math. Soc., 347 (1995), 2941-2960.

[8] D. Cruz-Uribe And C. J. Neugebauer, Weighted norm inequalities for the geometric maximal operator, Publ. Mat., 42 (1998), 239-263.

[9] D. Cruz-Uribe, C. J. Neugebauer ANd V. Olesen, Weighted norm inequalities for geometric fractional maximal operators, J. Fourier Anal. Appl, 5 (1999), 45-66.

[10] D. CRUZ-URIBE, The minimal operator and the geometric maximal operator in $R^{n}$, Studia Math., 144 (2001), 1-37.

[11] H. L. Zuo AND P. D. LiU, The minimal operator and weighted inequalities for martingales, Acta Math. Scientia (B), 26 (2006), 31-40.

[12] H. L. Zuo AND P. D. LIU, Weighted inequalities for the geometric maximal operator on martingale spaces, Acta Math. Scientia (B), 28 (2008), 81-85.

[13] E. T. SAWYER, A characterization of a two weight norm inequality for maximal operators, Studia Math., 75 (1982), 1-11.

[14] R. L. Long AND L. Z. Peng, Two weighted maximal $(p, q)$ inequalities in martingale setting, Acta Math. Sinica, 29 (1986), 253-258. 